Journal of Liquid Chromatography \& Related

Technologies

2001; 24(13) : 1979 - 1985

http://dx.doi.org/10.1081/JLC-100104439

(c) 2001 Taylor \& Francis

The original publication is available at http://www.tandf.co.uk/journals/
Archimer http://www.ifremer.fr/docelec/ Archive Institutionnelle de l'Ifremer

\title{
Comments on Van Deemter plot in high speed countercurrent chromatography
}

\author{
Alain Berthod ${ }^{1}$ and Alain Foucault ${ }^{2}$
}

${ }^{1}$ Université de Lyon1, Laboratoire des Sciences Analytiques, 69622, Villeurbanne, France

${ }^{2}$ IFREMER, Laboratoire de Biochimie et Molécules Marines, 44311, Nantes, France

\begin{abstract}
An inaccuracy in the computation of the linear mobile phase velocity rendered the whole content of a recently published article, Q.Z. Du, P.D. Wu, Y, Ito, J. Liq. Chromatogr. \& Rel. Technol., 23(19), 2929 (2000), erroneous. Since the stationary phase volume was given, the correct mobile phase velocity values were computed and the new values for the Van Deemter plots of three compounds are listed. It is concluded that the $1.5 \mathrm{~mL} / \mathrm{min}$ flow rate, corresponding to the minimum of the Van Deemter plots, or the maximum efficiency, does not justify calling the technique High Speed CCC since three hours are needed to develop the chromatogram.
\end{abstract}

Keywords: plot, computation, phase, chromatogram 


\title{
COMMENTS ON VAN DEEMTER PLOT IN HIGH SPEED COUNTERCURRENT CHROMATOGRAPHY
}

\author{
Alain, Berthod ${ }^{1}$, Alain Foucault ${ }^{2}$ \\ ${ }^{1}$ Laboratoire des Sciences Analytiques \\ Université de Lyon1, CNRS 5619 \\ Bat. 308, CPE Lyon \\ 69622 Villeurbanne, France \\ ${ }^{2}$ Laboratoire de Biochimie et Molécules Marines \\ IFREMER, CNRS \\ BP 1105, rue de l'Isle d'Yeu \\ 44311 Nantes, France
}

\begin{abstract}
An inaccuracy in the computation of the linear mobile phase velocity rendered the whole content of a recently published article, Q.Z. Du, P.D. Wu, Y, Ito, J. Liq. Chromatogr. \& Rel. Technol., 23(19), 2929 (2000), erroneous. Since the stationary phase volume was given, the correct mobile phase velocity values were computed and the new values for the Van Deemter plots of three compounds are listed. It is concluded that the $1.5 \mathrm{~mL} / \mathrm{min}$ flow rate, corresponding to the minimum of the Van Deemter plots, or the maximum efficiency, does not allow to call the technique High Speed CCC since three hours are needed to develop the chromatogram.
\end{abstract}

\section{INTRODUCTION}

In a recent work $^{1}$ titled: "Van Deemter Plot in High Speed Countercurrent Chromatography with a Fixed Volume of Stationary Phase", Du et al. used the classical Van Deemter equation:

$$
\mathrm{H}=\mathrm{A}+\mathrm{B} / \mathrm{u}+\mathrm{Cu}
$$


to investigate solute band broadening observed in a hydrodynamic CCC machine at different flow rates. In the Van Deemter equation, $\mathrm{H}$ is the height equivalent to a theoretical plate, in $\mathrm{cm}$, $\mathrm{u}$ is the mobile phase linear velocity, in $\mathrm{cm} \mathrm{s}^{-1}, \mathrm{~A}, \mathrm{~B}$ and $\mathrm{C}$ are three constants. $\mathrm{A}$, in $\mathrm{cm}$, expresses the broadening contribution due to different possible paths that the solute molecules can follow. $\mathrm{B}$, in $\mathrm{cm}^{2} \mathrm{~s}^{-1}$, represents the band broadening contribution due to longitudinal diffusion and $\mathrm{C}$, in $\mathrm{s}$, is the contribution of the kinetic of the solute transfer from the mobile phase to the stationary phase and vice versa. Three different solutes were used. They were epigallocatechin gallate (EGCG), gallocatechin gallate (GCG) and epicatechin gallate (ECG).

The aim of these comments is to rectify serious inaccurate statements found in this article.

\section{FLOW RATE AND LINEAR VELOCITY}

It is essential to have the correct value of the linear mobile phase velocity in order to derive significant A, B and C constants in the Van Deemter equation. The linear velocity, $\mathrm{u}$, is depending on the flow rate, F, the column length, L, and the mobile phase volume, $\mathrm{V}_{\mathrm{m}}$, present in the chromatographic column:

$$
\mathrm{u}=\mathrm{FL} / \mathrm{V}_{\mathrm{m}}
$$

Unfortunately, in the cited work ${ }^{1}$, the stationary phase was ignored and the inside tubing volume, $\mathrm{V}_{\mathrm{C}}$, was used in Eq. 2 in place of $\mathrm{V}_{\mathrm{m}}$. Since the stationary phase volume was $22 \mathrm{~mL}$, the $\mathrm{V}_{\mathrm{C}}$ volume was $54 \mathrm{~mL}$, it is easy to calculate the mobile phase volume, $\mathrm{V}_{\mathrm{m}}=32 \mathrm{~mL}$. The stationary phase retention factor is $\mathrm{Sf}=41 \%$. This incorrectness introduces a systematic bias of $\sim 40 \%$ by default in the whole set of $u$ values used in Ref. 1 . Table 1 lists the correct $u$ values along with the plate number corresponding to the experiments exposed in Ref. 1.

The consequences of this inaccuracy on mobile phase flow rates are that the fitted parameters are dramatically changed. Table 2 lists the A, B and C parameters obtained using the method presented in Ref. 2. Figure 1 shows the experimental points plotted with the fitted Van Deemter curves. The comparison of the correct values, listed in Table 2, with the published values shows the dramatic consequences that a change in the set of $u$ values may have on the fitted A, B and C parameters. The A parameter is no more a constant. It depends on the distribution coefficient, $\mathrm{K}$, as well as the $\mathrm{B}$ and $\mathrm{C}$ values. However, the plot A versus $\mathrm{K}$ is certainly not linear (Figure 2). The regression coefficients obtained for the plots of $B$ and $C$ versus $K$ are indicated in the figure. These variations are in accordance with that encountered in several chromatographic models such as the plug flow model with axial dispersion. ${ }^{3}$ 
But it should be noted that three points are not enough to draw any strong conclusion.

\section{USING LOGARITHMS}

The work finishes showing plots of $\log \mathrm{H}$ versus $\log \mathrm{u}$ and stating "Figure 3 shows the plot of $\log \mathrm{H}$ versus $\log \mathrm{u}$, indicating a linear correlation between these two parameters when $u$ is $1 \mathrm{~cm} / \mathrm{s}$ or greater." This is highly misleading. It is known that the logarithm function applied to any set of data produces a strong compression. A variation of one order of magnitude is converted in one log unit. If further compression is added using different scale for the $\mathrm{X}$ and $\mathrm{Y}$-axis (Figure 3, top), any function can be linearized in the log$\log$ space. Since the equation of the Van Deemter relation is known (Eq. 1), it is obvious that for high $\mathrm{u}$ values, the $\mathrm{B} / \mathrm{u}$ term becomes small and $\mathrm{H}$ tends toward the $\mathrm{Cu}$ line. Figure 3 (bottom) shows the plots of $\log \mathrm{H}$ versus $\log \mathrm{u}$ in adjusted $\mathrm{X}$ and Y-axis. The compressed Van Deemter plot is apparent, compare with Figure 1.

\section{BAND BROADENING IN A CCC MACHINE}

The importance of the stationary phase volume inside the CCC machine was pointed out early. ${ }^{4,5}$ Some results obtained with a variable stationary phase volume could be questionned. ${ }^{6}$ It remains interesting to see that, with a constant stationary phase volume, the behavior of a hydrodynamic CCC machine is classical. It should also be pointed out that the low efficiency of the machine used (plate numbers are listed in Table 1) produced broad peak. If the compounds were not injected one by one, the results listed may have a high uncertainty. Figure 4 shows the chromatograms recalculated with the published data. At a $16 \mathrm{~mL} / \mathrm{min}$-flow rate, the peak efficiency measurement was not possible. At $2 \mathrm{~mL} / \mathrm{min}$ (Figure 4, inset), the peak efficiencies were maximal and the measurement was accurate. The problem of the results exposed in Ref. 1 is that it is shown that the maximum efficiency is obtained between flow rates of 1 and $2 \mathrm{~mL} / \mathrm{min}$, say about $1.5 \mathrm{~mL} / \mathrm{min}$. At this flow rate, the experiment duration is more than three hours to separate compounds with distribution coefficients of 6 (Figure 4). Is it still possible to say this form of CCC is "High Speed"? 


\section{REFERENCES}

1. Q.Z. Du, P.D. Wu, Y, Ito, J. Liq. Chromatogr. \& Rel. Technol., 23(19), 2929 (2000).

2. A. Berthod, J. Liq. Chromatogr., 12(7), 1169 (1989).

3. G. Banestos, P.E. Barker, Eds., Preparative and Production Scale Chromatography, M. Dekker, New York, 1992.

4. O. Bousquet, A.P. Foucault, F. Le Goffic, J. Liq. Chromatogr., 14(18), 3343 (1991).

5. A.P. Foucault, O. Bousquet, F. Le Goffic, J. Cazes, J. Liq. Chromatogr., 15(15\&16), 2721 (1992).

6. D.W. Armstrong, G.L. Bertrand, A. Berthod, Anal. Chem., 60, 2513 (1988). 
Table 1. Linear Mobile Phase Velocities and Peak Plate Numbers at Different Flow Rates.

\begin{tabular}{|c|c|c|c|c|c|c|c|}
\hline \multirow[b]{2}{*}{$\begin{array}{c}\mathbf{F} \\
\mathrm{mL} / \mathrm{min}\end{array}$} & \multirow[b]{2}{*}{$\begin{array}{c}\mathbf{u} \\
\mathrm{cm} / \mathrm{s}\end{array}$} & \multicolumn{2}{|c|}{ EGCG } & \multicolumn{2}{|c|}{ GCG } & \multicolumn{2}{|c|}{ ECG } \\
\hline & & $\begin{array}{c}\mathbf{H} \\
\mathbf{c m}\end{array}$ & $\begin{array}{c}\mathbf{N} \\
\text { plates }\end{array}$ & $\begin{array}{c}\mathbf{H} \\
\mathbf{c m}\end{array}$ & $\begin{array}{c}\mathbf{N} \\
\text { plates }\end{array}$ & $\begin{array}{c}\mathbf{H} \\
\mathbf{c m}\end{array}$ & $\begin{array}{c}\mathbf{N} \\
\text { plates }\end{array}$ \\
\hline 16 & 8.33 & 36.70 & 27 & 41.5 & 24 & 51.67 & 19 \\
\hline 12 & 6.25 & 28.42 & 35 & 33.5 & 30 & 38.98 & 26 \\
\hline 8 & 4.17 & 22.72 & 44 & 25.3 & 39 & 32.40 & 31 \\
\hline 4 & 2.08 & 15.47 & 65 & 17.7 & 56 & 21.99 & 45 \\
\hline 3.2 & 1.67 & 12.62 & 79 & 15.9 & 63 & 19.50 & 51 \\
\hline 2 & 1.04 & 11.01 & 91 & 14.3 & 70 & 18.22 & 55 \\
\hline 1 & 0.52 & 12.08 & 83 & 15.2 & 66 & 20.47 & 49 \\
\hline 0.5 & 0.26 & 12.35 & 81 & 15.7 & 64 & 22.73 & 44 \\
\hline
\end{tabular}

The $\mathrm{H}$ values, in $\mathrm{cm}$ per theoretical plate, come from Ref. [1].

Table 2. Van Deemter coefficients for the Table 1 Data Set and Solutes Retention Volumes and Distribution Coefficients.

$\begin{array}{cccc}\text { solute } & \text { EGCG } & \text { GCG } & \text { ECG } \\ \mathrm{A}(\mathrm{cm}) & 6.1 & 8.8 & 10.6 \\ \mathrm{~B}\left(\mathrm{~cm}^{2} \mathrm{~s}^{-1}\right) & 1.5 & 1.7 & 3 \\ \mathrm{C}(\mathrm{s}) & 3.7 & 3.9 & 4.8 \\ & & & \\ \operatorname{Vr}(\mathrm{mL}) & 56 & 85.5 & 164 \\ \mathrm{~K} & 1.1 & 2.35 & 6.0\end{array}$




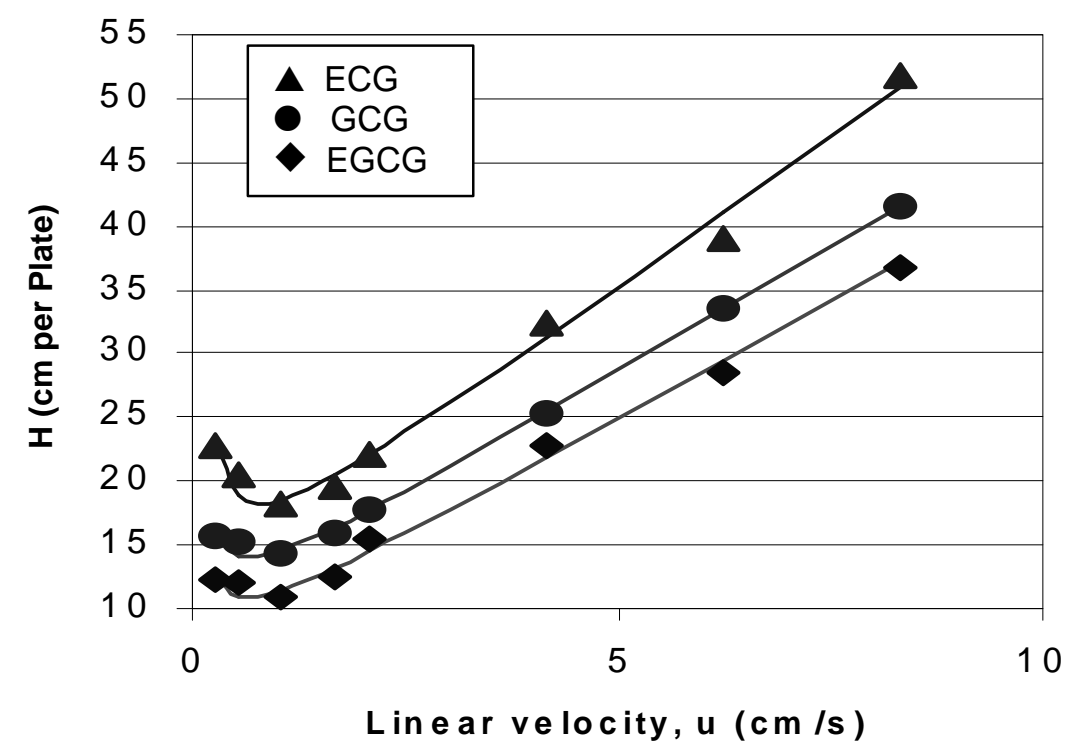

Figure 1. Van Deemter plots for the experimental data of Ref. 1 and the $u$ values of Table 1. The lines correspond to equation 1 with $\mathrm{A}, \mathrm{B}$ and $\mathrm{C}$ values of Table 2 .

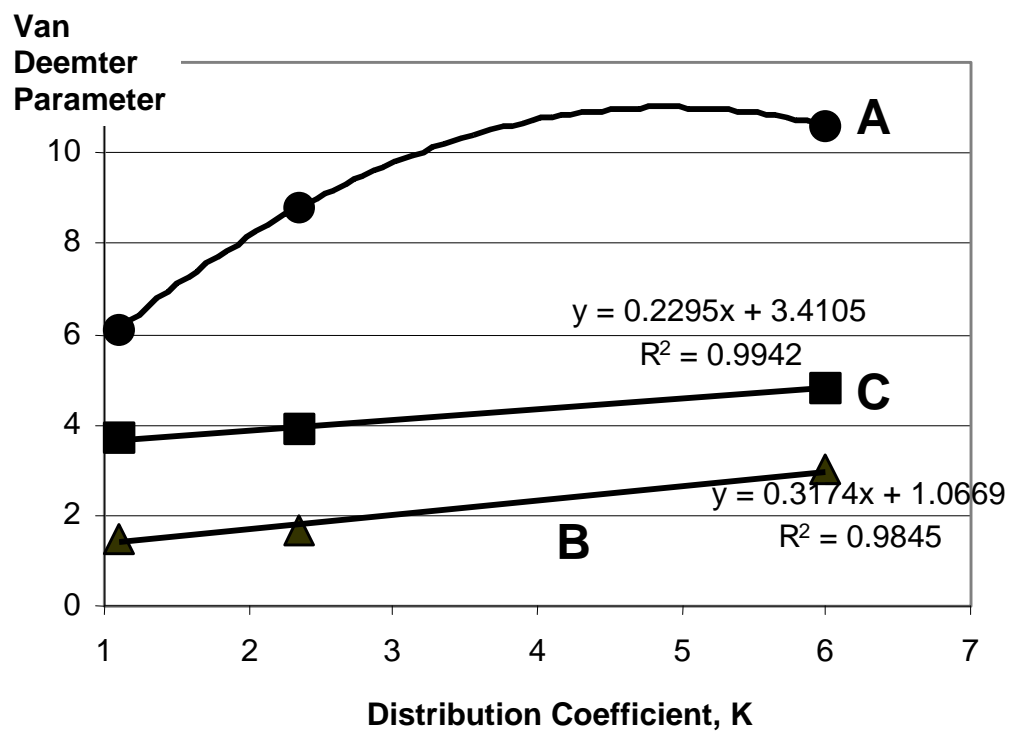

Figure 2. Van Deemter coefficients A, B and C plotted versus the solute distribution coefficients. 

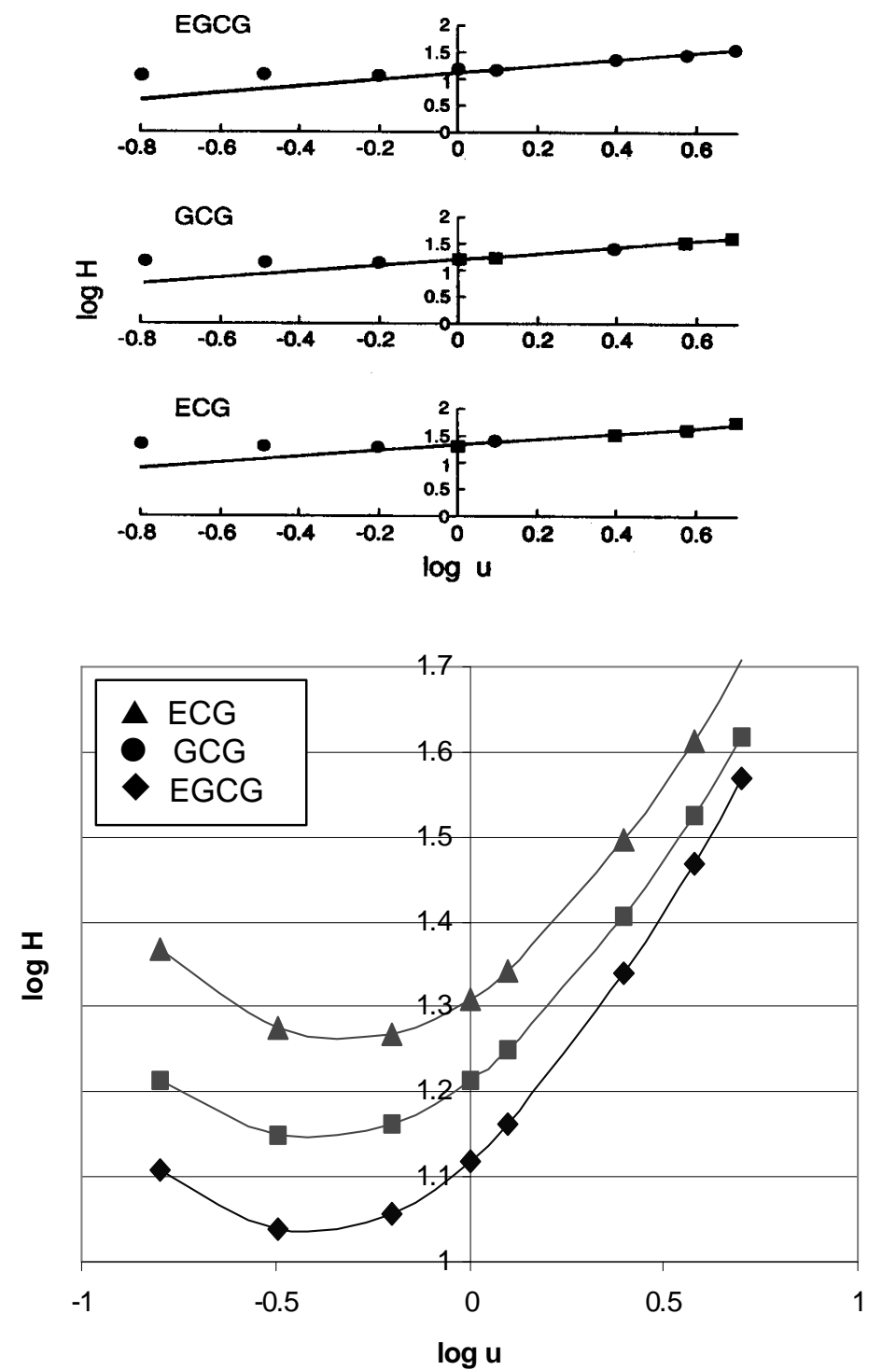

Figure 3. Plots of $\log \mathrm{H}$ versus $\log \mathrm{u}$. Top: verbatim of the Ref. 1 Figure 3 published plot; Bottom: plot with correct parameters (Table 2) and axis scale. 


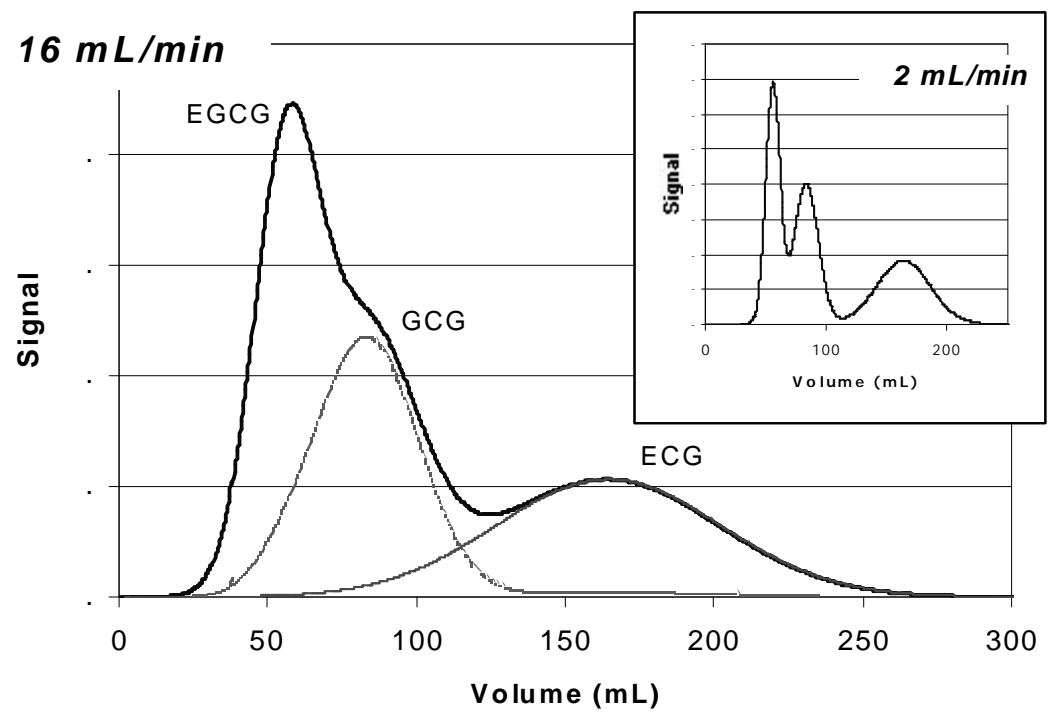

Figure 4. Reconstructed chromatograms using the data published in Ref. 1 at two different flow rates. Experiment duration: $19 \mathrm{~min} @ 16 \mathrm{~mL} / \mathrm{min}$ and $125 \mathrm{~min} @ 2$ $\mathrm{mL} / \mathrm{min}$. 